\title{
Shear Behavior of Non-Persistent Joint under High Normal Load
}

\author{
V. Sarfarazi, ${ }^{a}$ H. Haeri, ${ }^{\text {b,1 }}$ A. B. Shemirani, ${ }^{\text {c }}$ and Z. Zhu ${ }^{\mathrm{d}}$ \\ a Department of Mining Engineering, Hamedan University of Technology, Hamedan, Iran \\ ${ }^{\mathrm{b}}$ Department of Civil Engineering, Sharif University of Technology, Tehran, Iran \\ ${ }^{c}$ Department of Civil Engineering, SADRA Institute of Higher Education, Tehran, Iran \\ ${ }^{d}$ College of Architecture and Environment, Sichuan University, Chengdu, China \\ ${ }^{1}$ haerihadi@gmail.com
}

УДК 539.4

\section{Поведение нестабильного соединения при сдвиге при воздействии интенсивной нормальной нагрузки}

\author{
В. Сарфарази ${ }^{\mathrm{a}}$, Х. Хаэри ${ }^{\sigma}$ А. Б. Шемирани ${ }^{\mathrm{B}}$ Ж. Жу ${ }^{\mathrm{r}}$ \\ a Хамаданский технологический университет, Хамадан, Иран \\ ${ }^{\sigma}$ Факультет гражданского строительства, Технологический университет Шариф, Тегеран, Иран \\ в Факультет гражданского строительства, САДРА институт, Тегеран, Иран

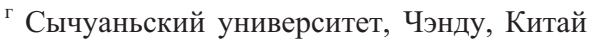

Исследовано влияние разъединения соединения при сдвиге плоского нестабильного соединения под действием интенсивной нормальной нагрузки с использованием программного обеспечения PFC2D. Первоначально калибровка PFC2D проведена на основе экспериментальных данных для согласования с моделируемым числовым результатом. Достоверность моделируемых моделей проверена при сравнении с результатами прямых испытаний на сдвиг, выполненных на нестабильных сочлененных физических моделях. Благодаря числовому прямому испьтанию на сдвиг прочесс разрушения был отмечен визуально, и разрушенные образиь отбирались подобными экспериментально наблюдаемым тенденциям. Дискретное моделирование элемента показывает, что на разрушение образиа главным образом влияет разъединение соединения, в то время как прочность при сдвиге связана с моделью разрушения и механизмом разрушения.

Ключевые слова: программное обеспечение PFC2D, нестабильное соединение, разъединение соединения, трещины сдвига и растяжения.

Introduction. The rock mass is composed of non-persistent joints and intact rock [1]. The shear sliding of non-persistent joints is important factor controlling the mechanical behavior of rock masses [2]. Therefore, a study on the shear failure behavior of nonpersistent joint can provide a good understanding of both local and general rock instabilities, leading to an improved design for rock engineering projects. Lajtai [3, 4], tensile wing cracks were found to first appear at the tips of horizontal joints, followed by the secondary shear cracks propagating towards the opposite joint. Savilahti et al. [5] did some further study on the specimens with jointed rock under direct shear testing where the joint separation varies in both horizontal and vertical directions and joint arrangement changes from non-overlapping to overlapping using modelling material. The coalescence patterns for specimens indicated that, the jointed rock failed in mixed and tensile modes for non-overlapping and overlapping joint configurations, respectively. Wong et al. [6] studied 
shear strength and failure pattern of rock-like models containing arrayed of open joints in both modelling plaster material and natural rocks under direct shear tests. Results showed that failure pattern was mainly controlled by the joint separation while shear strength of jointed rock depended mostly on the failure pattern.

Ghazvinian et al. [7] made a thorough analysis of the shear behavior of the rock-bridges based on the change in the persistence of their area. The analysis proved/ showed that the failure mode and mechanism are under the effect of the continuity of the rock-bridge.

In recent years, numerical modelling techniques for fracturing process simulation have been widely used in rock engineering. In general, many established numerical techniques can be used, i.e., the finite element method $[8,9]$, the boundary element method [10-16] or the displacement discontinuity method. In recent decades, numerous theories for predicting stress distribution and crack propagation have been proposed. For most practical purposes, the three fundamental theories commonly employed are [17]: maximum tangential stress theory [18], maximum energy release rate theory [19], and minimum energy density theory [20].

In [21-27], studied crack initiation, propagation and coalescence using Particle Flow code (PFC2D). In many cases, there are similarities between the results for crack initiation and coalescence through numerical analysis and laboratory testing. Using smooth-joints would be preferential in modelling the mechanical behaviors of a joint in PFC. Many PFC users have reported the successes, failures and difficulties encountered during the PFC usage. The shear behavior of non-persistent joint using PFC2D has not been investigated in any previous researches.

In this paper, a particle flow code is used to study the shear failure behavior of non-persistent joint under high normal load. Also, the ability of PFC2D in determining the failure patterns in rock bridges has been checked by comparison of the numerical and experimental results. For this purpose, using an inverse-modelling calibration approach, the laboratory results of the uniaxial, Brazilian and triaxial tests were used to obtain the estimates of the intact rock micromechanical parameters used in the simulation. A validation of the simulation was then performed by comparison between the shear behavior of rock bridges in PFC2D and that of the non-persistent joint tested under direct shear loading in the laboratory. The validated numerical model was used to further studying the mechanical behavior of the jointed models with different joint persistency.

\section{Laboratory Tests.}

1.1. Model Material Preparation. The model material used in preparing the intact samples and jointed blocks was a mixture of plaster $(37.5 \%)$, cement $(25 \%)$, and water $(37.5 \%)$. Mixing, casting, curing of the specimens and their dimensions has been described in details by Sarfarazi et al. [27]. The uniaxial/triaxial compression and the Brazilian tensile tests were performed in Rock Mechanics Laboratory of Graz University of Technology (Austria) by the Machine Tool System (MTS) in order to determine the mechanical properties of intact model material (Table 1).

T a b 1 e 1

Property Values of the Intact Model Material Determined Experimentally

\begin{tabular}{|c|c|}
\hline Property & Value \\
\hline Average uniaxial compressive strength $(\mathrm{MPa})$ & 6.6 \\
\hline Average Brazilian tensile strength ( $\mathrm{MPa})$ & 1.0 \\
\hline Average elastic modulus in compression ( $\mathrm{GPa})$ & 5.4 \\
\hline Average Poisson's ratio & 0.18 \\
\hline Internal angle of friction (deg) & 20.4 \\
\hline Cohesion (MPa) & 2.2 \\
\hline
\end{tabular}


1.2. Intact Model Material Properties. The uniaxial, triaxial compression and Brazilian tensile tests were performed in order to determine the mechanical properties of the intact model material. The mechanical properties of the physical models are summarized in Table 1.

1.3. Preparation, Testing and Results of the Rock-Like Model Consisting of Non-Persistent Joints. The mold dimensions for discontinuous jointed samples were $150 \mathrm{~mm}$ in length, $150 \mathrm{~mm}$ in width, and $150 \mathrm{~mm}$ in thickness. The mold is consisted of four 20-mm-thick fibreglass sheets bolted together plus two fibreglass plates (placed at the top and bottom of the mold) (Fig. 1). The top plate has two orifice openings used to fill the mold with the liquid mixture. The upper and the lower surfaces have slits cut into them. The opening of the slits is $1 \mathrm{~mm}$, and their tract is equal to the width of the model. Through these slits, greased metallic shims are inserted through the thickness of the mold (to produce non-persistent joints) before pouring of the gypsum. Each sample was kept in the mold for about $7 \mathrm{~h}$, the specimens were un-molded, and the metallic shims were pulled out of the specimens. The grease on the shims prevents adhesion of the shim with the sample and facilitates the removal of the shims. As the mixture is placed and hardened, each shim leaves an open joint in the specimen through the thickness and perpendicular to the front and back of the specimen. It appears that the pulling out of the shims does not produce any damage to the joints. Immediately after removing of the shims, the specimen is stored in the laboratory room with the temperature controlled at $20 \pm 2^{\circ} \mathrm{C}$ for 20 days. It is important to note that consistency in mixing, casting, curing and testing is required to obtain acceptable test results.

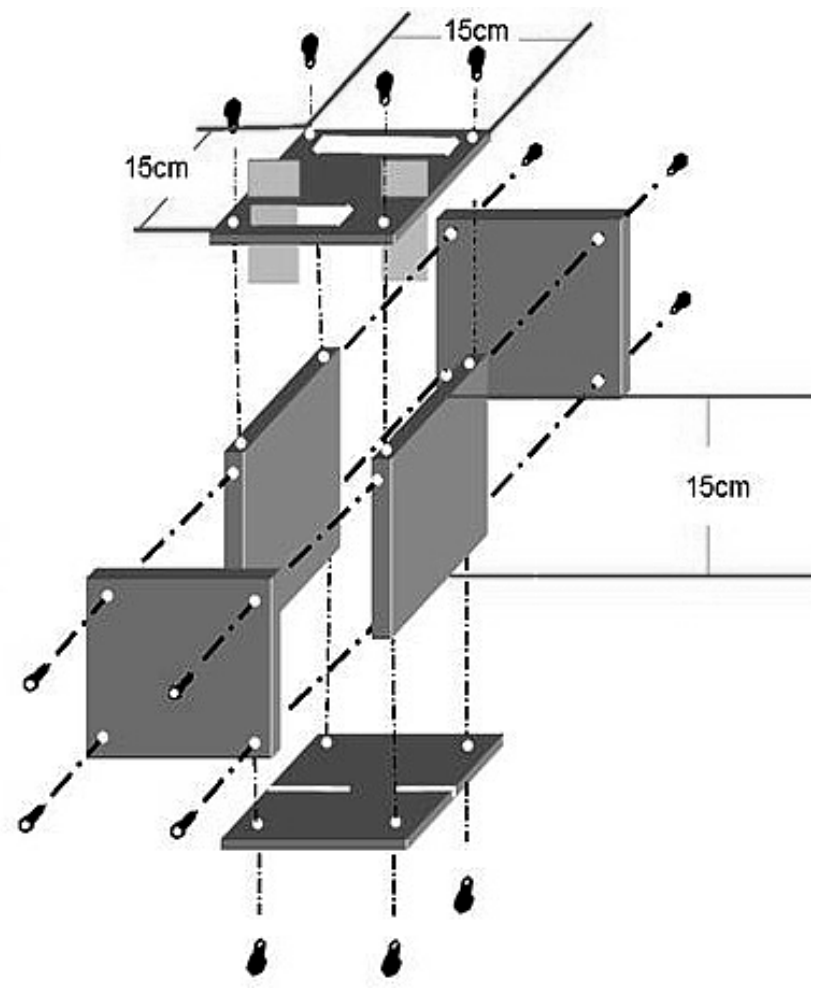

Fig. 1. Mold used for fabrication of the jointed specimens.

Three specimens with different rock bridge surface of 34,68 , and $135 \mathrm{~cm}^{2}$ were prepared (Fig. 2). Based on the change in the surface of the non-persistent joints, it is possible to define the joint coefficient $(J C)$ as the ratio of the joint surface to the total shear surface, $225 \mathrm{~cm}^{2}$. The values of $J C$ for three specimens are $0.4,0.7$, and 0.85 . 


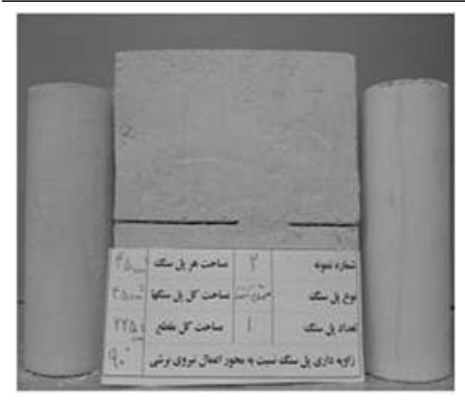

a

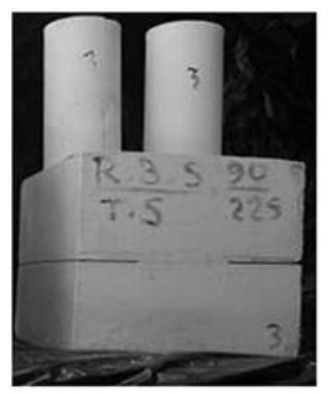

b

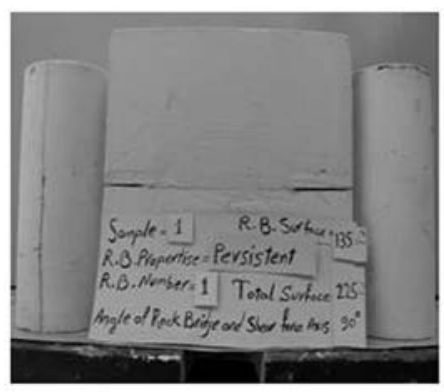

$\mathrm{c}$

Fig. 2. Views of the non-persistent joint: (a) rock bridge surface is $34 \mathrm{~cm}^{2}$; (b) rock bridge surface is $68 \mathrm{~cm}^{2}$; (c) rock bridge surface is $135 \mathrm{~cm}^{2}$.

A servo-controlled MTS direct shear apparatus was used for the purpose of testing the artificial non-persistent joints. All samples were tested by applying a shear displacement rate of $0.01 \mathrm{~mm} / \mathrm{s}$. The high normal stress applied to the rock bridges was $2.5 \mathrm{MPa}$, which is approximately $38 \%$ of the uniaxial strength of intact sample. The shear loads as well as the shear displacements were taken by a data acquisition system during the shear test.

The crack pattern was observed after completion of the test. It was observed that the pre-existing joint surfaces have not been destroyed during the test. It means that the rock joint has no effect on the shear behavior of the rock bridge. The shearing process of a discontinuous joint constellation begins, as one would expect, with the formation of new fractures, which eventually transect the material bridges and lead to a through-going discontinuity. The observation results showed that the rock bridge surface influences the failure pattern of the rock bridge. Figure 3 shows the failure patterns obtained in the direct shear tests.

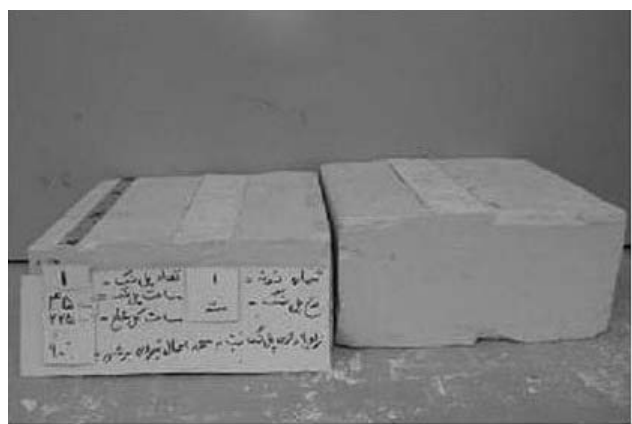

a

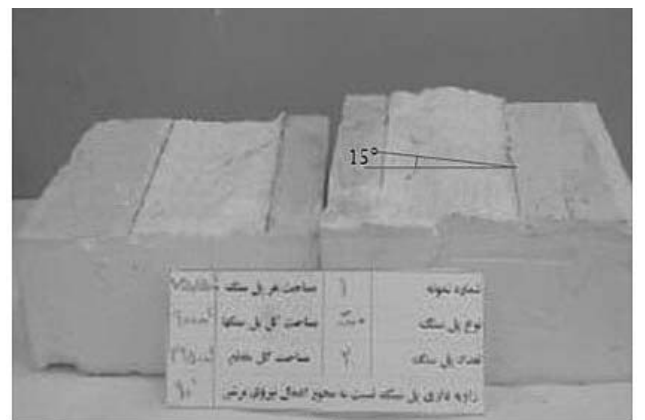

b

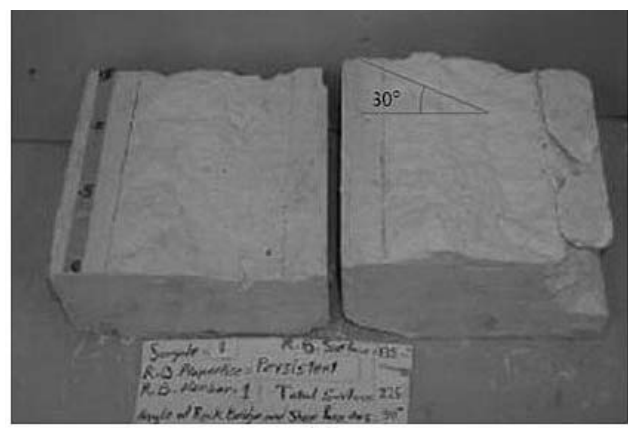

$\mathrm{c}$

Fig. 3. Failure patterns obtained in the direct shear tests: (a) $J C=0.85$; (b) $J C=0.7$; (c) $J C=0.4$. 
When $J C=0.4$ (Fig. 3a), the surface of failure at the bridge area is shear because crushed materials and evidence of shear movement were noticed. The shear surface plane is nearly horizontal with shear loading direction. The dilation angle is zero due to nonasperity effect of failure surface.

When $J C=0.7$ (Fig. 3b), the surface of failure at the bridge area is shear because pulverized materials and evidence of shear movement were noticed. The shear surface plane is undulating with asperity angle $15^{\circ}$. The dilation angle in this configuration is $4^{\circ}$ due to asperity effect of failure surface.

When $J C=0.85$ (Fig. 3c), the surface of failure at the bridge area is shear because pulverized materials exist in shear surface. The shear surface plane is undulating with asperity angle $30^{\circ}$. The dilation angle in this configuration is $8^{\circ}$ due to asperity effect of failure surface.

Figure 4 shows the variation of the failure stress and crack initiation stress versus the joint coefficient. The crack initiation stress is related to the stress whenever the sample initiates to dilate.

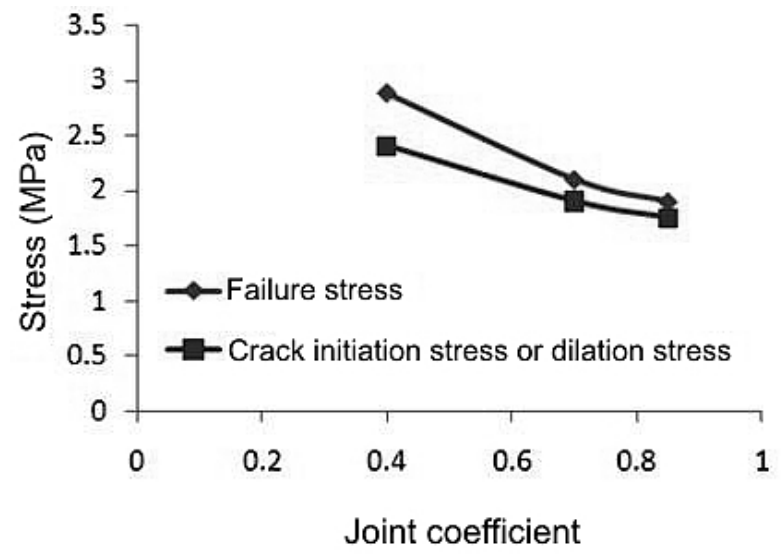

Fig. 4. Variation of the failure stress and crack initiation stress versus the joint coefficient.

The failure stress and the crack initiation stress are reduced by increasing the $J C$. When the $J C$ is high, 0.85 , the difference between the crack initiation stress and failure stress is low. It shows that the final failure is occurred as soon as the cracks are initiated within the rock bridge. It means that the brittle failure has been occurred. But when the $J C$ is low, 0.4, the difference between the crack initiation stress and failure stress is high. It shows that the final failure is occurred at the more loading steps after the cracks are initiated within the rock bridge. It means the progressive failure has been occurred.

2. Numerical Modelling with PFC.

2.1. Preparation and Calibration of the PFC2D Model for Rock-Like Material. The standard process of generating a PFC2D assembly to represent a test model, used in this study, is described in detail in [28]. The process involves: particle generation, packing the particles, isotropic stress installation (stress initialization), floating particle (floater) elimination and bond installation [29,30]. A gravity effect did not need to be considered as the specimens were small, and the gravity-induced stress gradient had a negligible effect on macroscopic behaviors.

Uniaxial compressive strength, Brazilian and biaxial tests were carried out to calibrate the properties of particles and the parallel bonds in bonded particle model [22, 27]. By adopting the microproperties listed in Table 2 and the standard calibration procedures [30], a calibrated PFC particle assembly was created. 
$\mathrm{T}$ a b 1 e 2

Microproperties Used to Represent the Intact Rock

\begin{tabular}{||l|c|c||}
\hline \multicolumn{1}{|c|}{ Property } & Experimental result & PFC2D model result \\
\hline Elastic modulus (GPa) & 5.4 & 5.0 \\
\hline Poisson's ratio & 0.18 & 0.19 \\
\hline Ultimate compression stress (MPa) & 6.6 & 6.7 \\
\hline Tensile strength (MPa) & 1.0 & 1.1 \\
\hline Friction angle (deg) & 20.4 & 21.0 \\
\hline Cohesion (MPa) & 2.2 & 2.2 \\
\hline \hline
\end{tabular}

\subsection{Numerical Direct Shear Tests on the Non-Persistent Open Joint.}

2.2.1. Preparing the Model. After calibration of PFC2D, direct shear tests for jointed rock were numerically simulated by creating a shear box model in the PFC2D (Fig. 5). The PFC specimen had the dimensions of $76 \times 60 \mathrm{~mm}$. A total of 11,179 disks with a minimum radius of $0.27 \mathrm{~mm}$ were used to make up the shear box specimen. The particles were surrounded by four walls. The planar non-persistent joints were formed by deletion of two non-persistent vertical bands of particles from the model. The opening of these notches is $1 \mathrm{~mm}$ (Fig. 5). To create the shear test condition, two horizontal narrow bands of particles, with the width of $1 \mathrm{~mm}$, were deleted from both the upper left side and the lower right side of the model at a distance between the joint walls and the shear box wall (Fig. 5). In total four specimens containing two planar edge-notched joints with different lengths were set up to investigate the influence of joint separation on the shear behavior of rock bridges. For different specimens, the lengths of these edge-notched joints were different, while in the same specimen, the lengths of those two joints were the same, and they are both arrayed in the vertical middle plane. The joint length $(b)$ has a range from 12 to $25.5 \mathrm{~mm}$ with an increment of $4.5 \mathrm{~mm}$, while the joint separation or ligament length $(l)$ decreases from 36 to $9 \mathrm{~mm}$ with a negative change value of $9 \mathrm{~mm}$. Based on the change in the length of planar non-persistent joints, it is possible to define the joint coefficient $(J C)$ as the ratio of the joint length to the total shear length, i.e., $2 b /(T+2 b)$. The value of $J C$ increases from 0.4 to 0.85 with an increment of 0.15 .

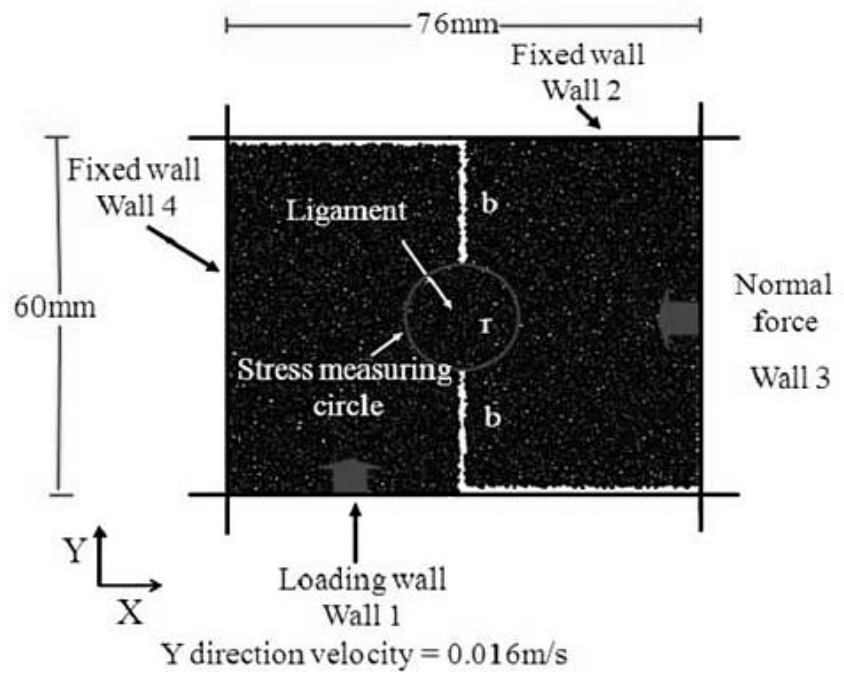

Fig. 5 Illustration of the direct shear test simulation scheme in PFC. 
2.2.2. Loading Setup. Both the upper and left walls of the shear box were fixed (Fig. 5). Shear loading was applied to the sample by moving the lower wall in the positive $Y$-direction, with an adequate low velocity (i.e., $0.016 \mathrm{~m} / \mathrm{s}$ ) to ensure a quasi-static equilibrium, while the normal stress was kept constant by adjusting the right wall's velocity using a numerical servo-mechanism. The normal stress applied to the rock bridges in the numerical tests was the same as in the laboratory tests (i.e., $2.5 \mathrm{MPa}$ ), which is approximately $38 \%$ of the uniaxial strength of the intact sample. Shear displacement was measured by tracing the lower vertical wall displacement (Fig. 5, wall 1 ). The shear force was registered by taking the reaction forces on the wall 2 in Fig. 5.

\section{Results and Discussion.}

3.1. Parallel Bond Forces in the Models before Crack Initiation. Figure 6 shows the parallel bond force distribution at a state before the crack initiation in four PFC samples, which have different values of $J C$ of $0.4,0.55,0.7$, and 0.85 , respectively. The dark and red lines represent the compression and tensile forces in the model, respectively. The coarser the line is, the larger the force is. As can be seen, the maximum force concentrations occur around the joint tips and also within the rock bridge area. When the joint coefficient was 0.85 (Fig. 6b), the maximum compressive force was equal to $2056 \mathrm{~N}$. The maximum tensile force, developed near the tip of the joint, was equal to $1658 \mathrm{~N}$. By decreasing the $J C$, the maximum tensile force at the joint tip is increased (Fig. 6) what explains the fact that the failure initiation stress increase by decreasing the joint surface continuity.

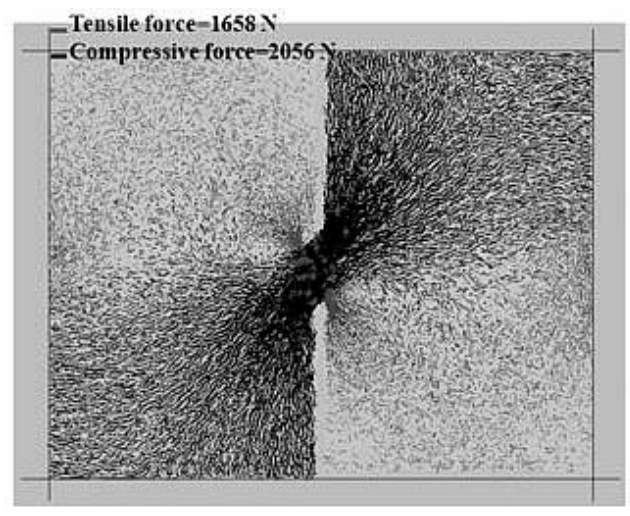

a

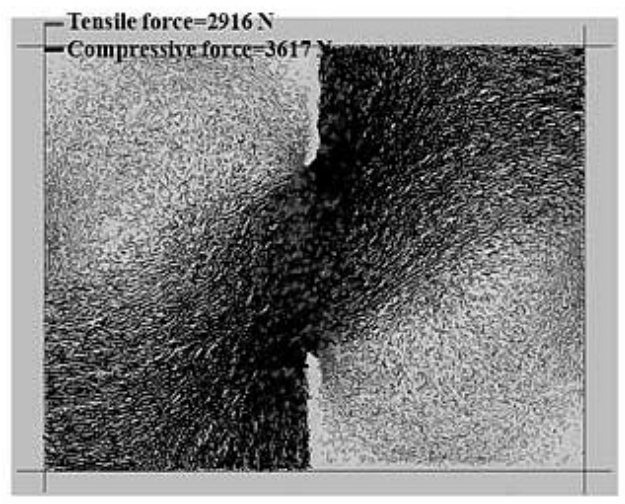

c

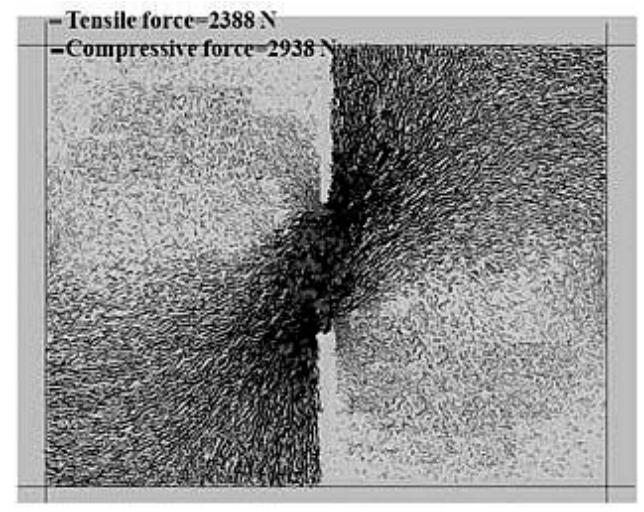

b

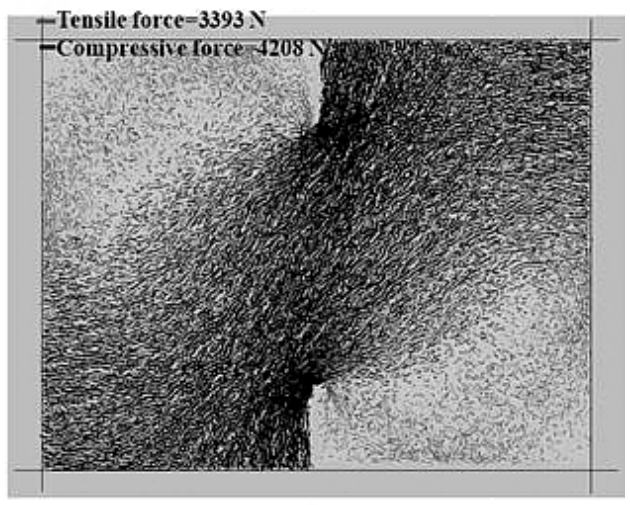

d

Fig. 6. The distribution of parallel bond forces in the models before the crack initiation occurs: (a) $J C=0.85$; (b) $J C=0.7$; (c) $J C=0.55$; (d) $J C=0.4$. 


\subsection{Influence of Joint Separation on the Failure Behavior of the Rock Bridge.} Figures 7, 8, 9, and 10 illustrate the fracture patterns recorded at three stages in the loading of the planar non-persistent joint for $J C=0.4,0.55,0.7$, and 0.85 , respectively (i.e., at the crack initiation stress stage of $A$, at the peak stress stage of $B$, and after the peak shear stress stage of $C$ where have been shown in the charts printed on these figures). In each $J C$, the evolution of the bond force at the three stages of fracture development was recorded. The dark and red lines represent compression forces and tensile forces, respectively; the coarser the line, the bigger the force acting at the model. Also at each stage of the simulation, the uncounter clockwise orientation of crack related to the loading direction and the number of shear and tension induced cracks were determined.

3.2.1. $J C=0.85$.

Stage A: As seen in Fig. 7a, before the peak shear stress is reached, only tensile fractures are initiated within the rock bridge and propagated for a short distance as a result of the release of tensile force. These cracks are categorized in the major fracture set of $F 0$
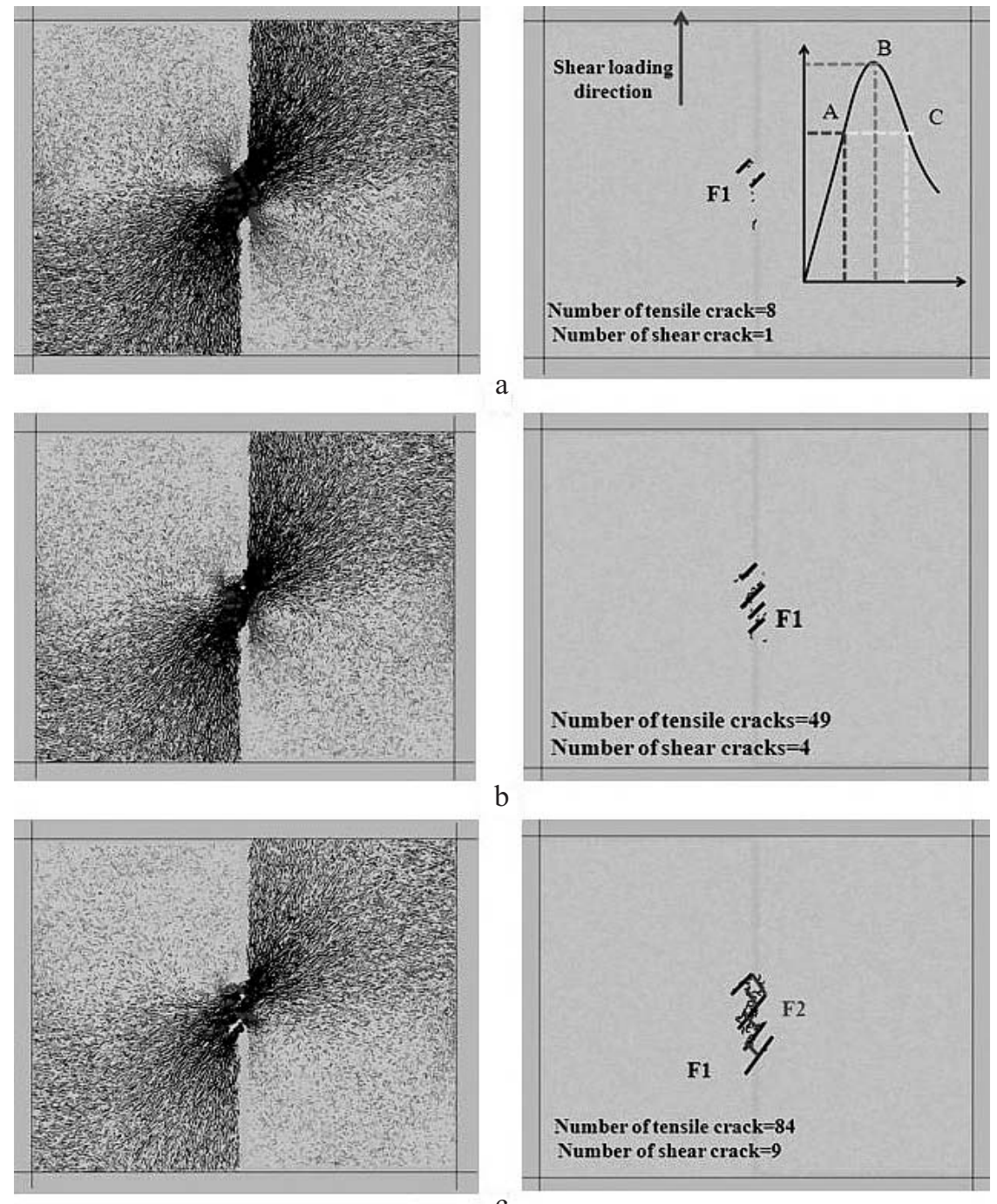

b

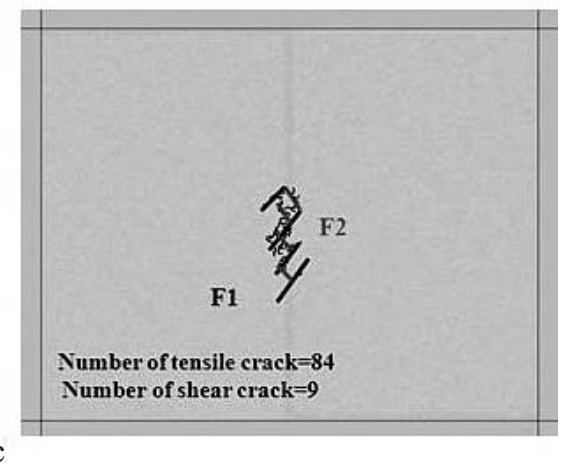

Fig. 7. Development of cracks, evolution of the bond force, and mean orientation of particle cracks during the three stages of shear loading. Here and in Figs. 8-10: (a) before beak, (b) at peak, and (c) after peak shear strength. 
with a mean orientation of $65^{\circ}$. The kinematic energy is released and transmitted into the neighbouring bonds. Since the force intensity at the unbroken bonds is not enough to rupture the contacts, the cracks develop in a stable manner.

Stage B: As seen in Fig. 7b, when the shear stress reaches the peak strength, the new tensile cracks are developed along the fracture set $F 1$ and propagate parallel to the maximum compressive force for a large distance. In this stage, four shear bands propagate within the rock bridge. The mean orientation of the fracture set, $F 1$, is $30^{\circ}$. The number of cracks in this step is 53 that are $57 \%$ of total number of cracks propagated in stage $C$. It means that when $57 \%$ of total cracks developed within the rock bridge, the shear strength is decreased and unstable crack growth is reached.

Stage $C$ : In the final stage, as shown in Fig. 7c, a new tensile fracture set, F2, develops in the vicinity of the fracture set of $F 1$ but in opposite direction and propagates for a short distance. The propagation length of fracture set $F 1$ in this stage is $2-3$ times more than the length of $F 3$ shear bands. The mean orientation of the two fracture sets of $F 1$ and $F 3$ is 30 and $320^{\circ}$, respectively.

The force distribution at this stage shows that the compressive force chains have developed in the model due to residual contact between the balls. The final failure occurs by breakage of these chains. It is worth noting that a few shear cracks are observed in the broken model as a result of breakage of shear bonds.

As can be seen from Fig. 3a, nearly the same failure pattern has occurred in the physical sample when $J C=0.85$.

3.2.2. $J C=0.7$.

Stage A: As seen in Fig. 8a, the upper and lower tensile cracks (in the fracture set, $F 0$ ) develop with a mean orientation of $60^{\circ}$ from the notch tips prior to the peak shear stress being attained. These propagate parallel to the maximum compressive force zone for a short distance. These fracture sets turn stable because of the release of tensile force with the development of tensile cracks. Following the bond breakage, the maximum tensile force is concentrated close to these two fracture sets.

Stage B: As the shear stress reaches the peak strength (Fig. 8b), the new tensile cracks that form the fracture set, $F 1$, develop at the midst of the rock bridge and propagate parallel to the maximum compressive force. The mean orientation of fracture set of $F 1$ is $35^{\circ}$. In this stage, the number of newly developed tensile cracks existing in the fracture set $F 1$ is more than that in the fracture set $F 0$. This means that the maximum tensile force has been transmitted within the rock bridge so several shear band develops in this area. The force distribution in the rock bridge shows that the maximum tensile force is concentrated near the broken bond.

The number of cracks in this step is 125 that are $59 \%$ of total number of cracks which propagate in stage $C$. It means that when $59 \%$ of total cracks developed within the rock bridge, the shear strength is decreased and unstable crack growth is reached.

Stage $C$ : In the final stage of the shear loading, as shown in Fig. 8c, tensile cracks develop near the fracture set, $F 1$. Also the tensile fracture set $F 2$ develops within the rock bridge and coalesces with the fracture set $F 1$ so that the intact bridge area gets split with an uneven shear failure surface. The mean orientation of two fracture sets, $F 1$ and $F 2$, is 40 and $330^{\circ}$, respectively. The propagation length of fracture set $F 1$ in this stage is nearly $2-3$ times more than the length of $F 2$ fracture set.

The length and orientation of fracture set $F O$ remain constant after the first stage of shear loading. It means that the external shear load does not induce any force concentration near the fracture set $F 0$ during the different stages of shear loading (stages of $B$ and $C$ ).

The bond force distribution at this stage shows that the force chains take an uneven form according to the geometry of the failure surface. These force chains are stable till the ultimate breakage occurs in the rock bridge. As can be seen from Fig. 3b, nearly the same failure pattern has occurred in the physical sample when $J C=0.7$. 

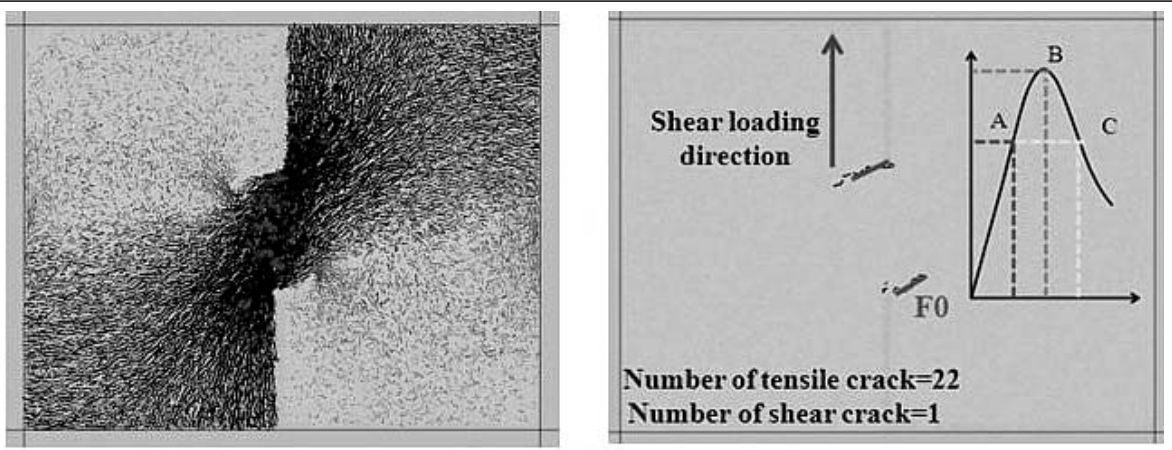

a
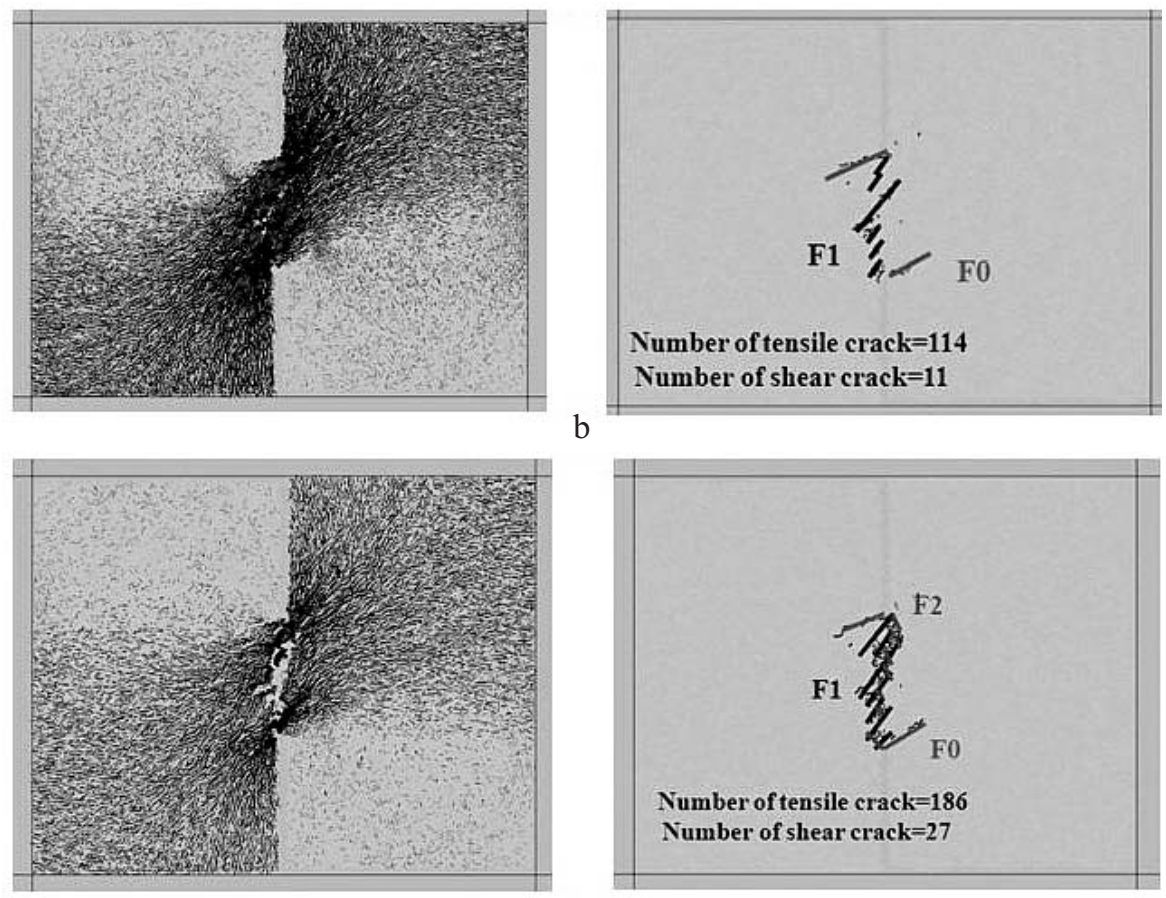

$\mathrm{c}$

Fig. 8. Development of cracks, evolution of the bond force, and mean orientation of particle cracks during the three stages of shear loading.

\subsection{3. $J C=0.55$.}

Stage A: As shown in Fig. 9a, before the peak shear stress is reached, the tensile fracture set of $F 1$ is identified in the bridge area with a mean orientation of $45^{\circ}$. This fracture set initiate near the joint tips where the tensile stress concentration is high. The fracture set $F 1$ propagate parallel to the maximum compressive force for a short distance and become stable.

Stage B: As the shear stress reaches the peak strength (Fig. 9b), the number of tensile fracture set $F 1$ is increased. These shear bands propagate parallel to the maximum compressive force for a large distance. The mean orientation of fracture set $F 1$ is equal to $50^{\circ}$. Force redistribution in the midst zone shows that the high tensile force is concentrated in vicinity of the fracture set $F 1$. The numbers of cracks in this step are 223 that are $62 \%$ of total number of cracks which propagate in stage $C$. It means that when $62 \%$ of total cracks developed within the rock bridge, the shear strength is decreased and unstable crack growth is reached. 

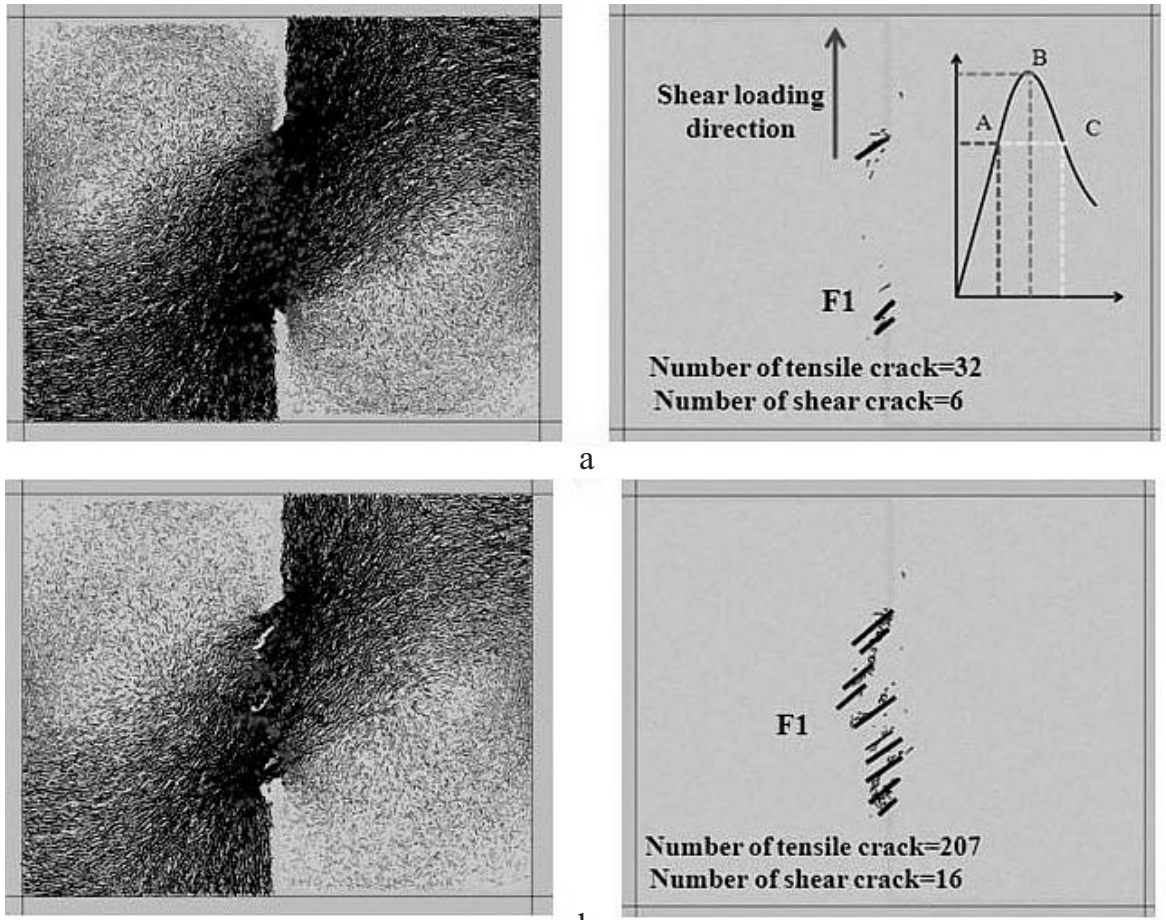

a
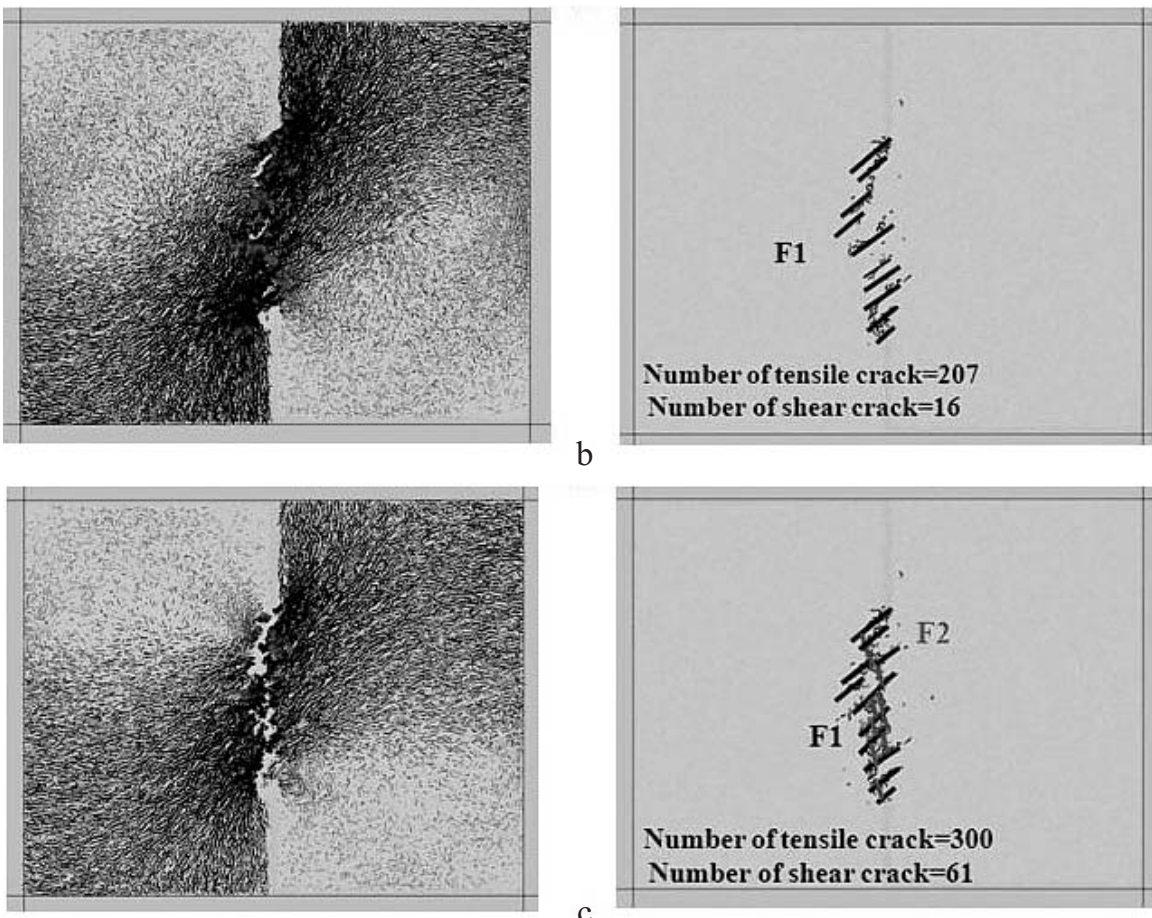

b

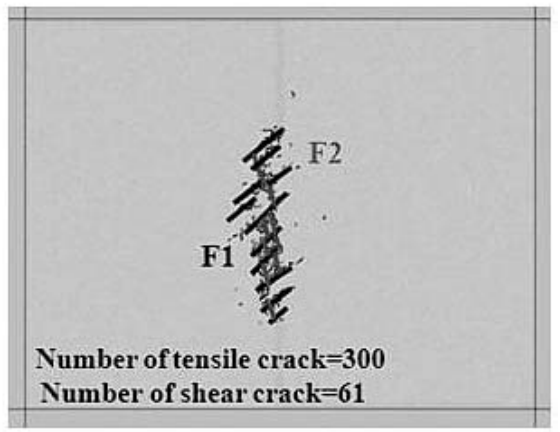

Fig. 9. Development of cracks, evolution of the bond force, and mean orientation of particle cracks during the three stages of shear loading.

Stage $C$ : In the final stage of the shear loading, as shown in Fig. 9c, the short tensile fracture set $F 2$ develops between the fractures set $F 1$ so that the intact bridge area gets broken with an unsymmetrical shear failure surface. The mean orientation of fracture set $F 2$ is $340^{\circ}$. The propagation length of fracture set $F 1$ in this stage is nearly $2-3$ times more than the propagation length of $F 2$ fracture set.

The bond force distribution shows that the force chains develop within the unbroken parts of the rock bridge. These chains affect the post peak behavior of the shear surface till the final breakage of the bonded particles is reached. Note that the tensile cracks are the dominant mode of failure, while a few shear cracks develop within the model.

\subsection{4. $J C=0.4$.}

Stage A: Figure 10a indicates that the tensile fracture set $F 1$ initiate at tip of the joint and propagate parallel to the maximum compressive force. The mean orientation of the tensile fracture set $F 1$ is $60^{\circ}$. Bond force distribution shows that the maximum tensile force is concentrated within the rock bridge. 
Shear Behavior of Non-Persistent Joint ...
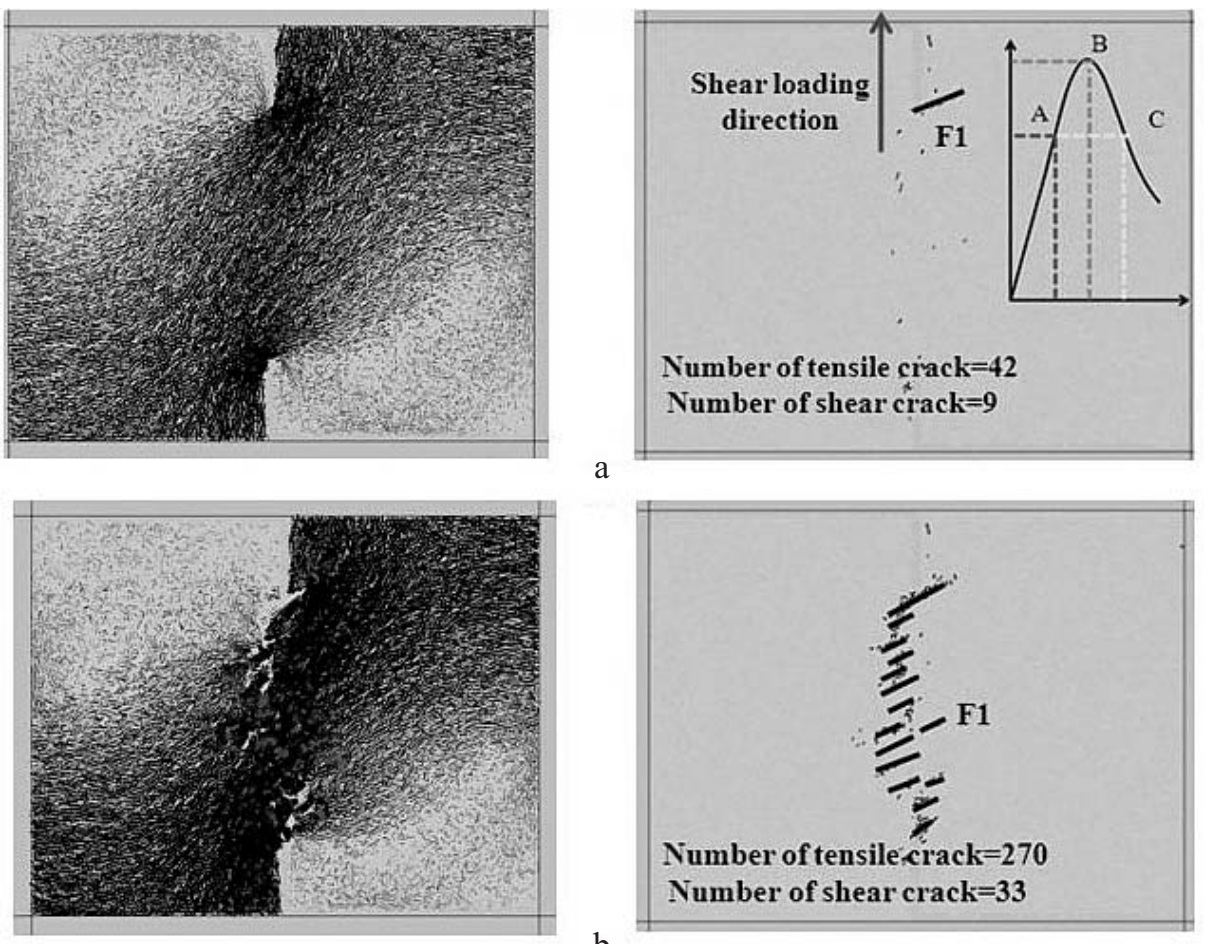

a

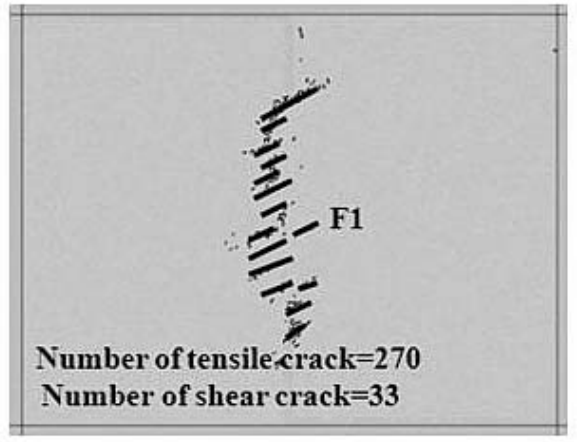

b
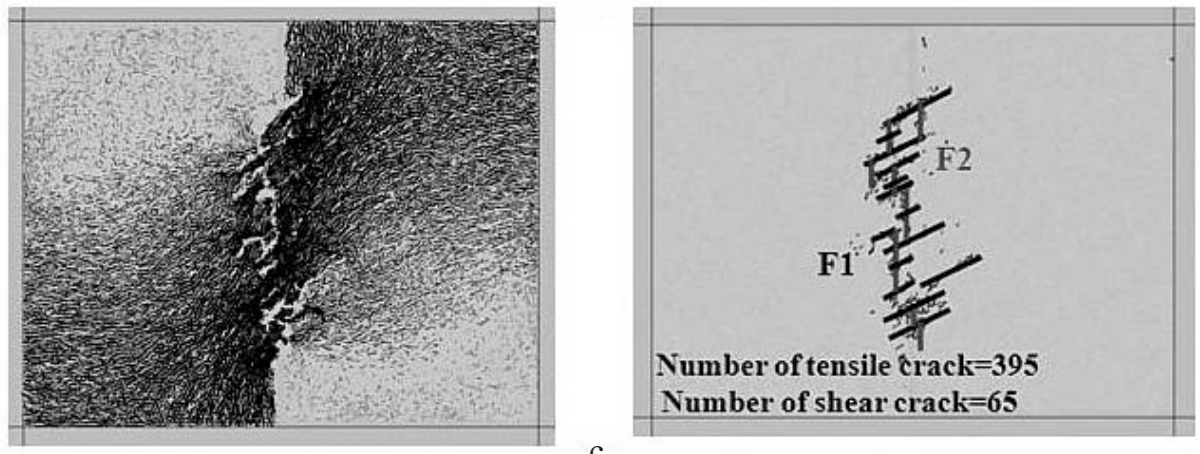

c

Fig. 10. Development of cracks, evolution of the bond force, and mean orientation of particle cracks during the three stages of shear loading.

Stage B: As the shear stress reaches the peak strength (Fig. 10b), new cracks (tensile/shear) develop parallel to the fracture set F1. The shear bands propagate parallel to the maximum compressive force for a large distance. The mean orientation of the tensile fracture set of $F 1$ is $60^{\circ}$. The force redistribution in the middle zone shows that the maximum forces are concentrated near the shear bands. The numbers of cracks in this step are 223 that are $65 \%$ of total number of cracks which propagate in stage $C$. It means that when $65 \%$ of total cracks developed within the rock bridge, the shear strength is decreased and unstable crack growth is reached.

Stage $C$ : In the final stage of shear loading (Fig. 10c), the short fracture set of $F 2$ consists of both shear and tensile cracks develops between the shear bands so that the intact bridge area gets broken with an unsymmetrical shear failure surface. The mean orientation of the tensile fracture set of $F 2$ is $355^{\circ}$. The propagation length of fracture set $F 1$ in this stage is $2-3$ times more than the propagation length of $F 2$ fracture set. 
The bond force distribution shows that the force chains develop within the unbroken rock bridge. The existence of bond forces in the rock bridge affects the residual strength of the broken model.

The numbers of cracks in this step are 303 that are $66 \%$ of total number of cracks which propagate in stage $C$. It means that when $66 \%$ of total cracks developed within the rock bridge, the shear strength is decreased and unstable crack growth is reached.

As shown in Fig. 3c, nearly the same failure pattern has occurred in the physical sample when $J C=0.4$.

From the above discussions, we can conclude that:

1. The tension cracks are considerably greater in number than the shear cracks. Such differences become even more significant as shear deformation increases.

2 . By decreasing the $J C$, the stable crack growth is increased what means that the more number of total cracks propagates in the stage of $B$.

3. The planar rock bridges under high normal load level break by several shear bands, $F 1$ and $F 2$.

4. By decreasing the $J C$, the mean orientation of the two tensile fracture sets of $F 1$ and $F 2$ are increased.

5. Two different tensile fracture sets develop within the rock bridges. The fracture set $F 1$ is observed at the peak shear stress (stage $B$ in Figs. 7-10), and the fracture set $F 2$ mainly is observed after the peak strength (stage $C$ in Figs. 7-10).

6 . When the joint coefficient is high, the stress interaction between the joints is so strong (Fig. 6) that two fracture sets of $F 1$ and $F 2$ with low orientation are responsible for breakage of the rock bridge. By decreasing the joint coefficient, the stress interaction between the joints is decreased (Fig. 6) and consequently the mean orientation of two tensile fracture sets of $F 1$ and $F 2$ are increased.

7. By decreasing the joint coefficient, the number and the length of the two fractures sets of $F 1$ and $F 2$ increase.

8. The propagation length of fracture set $F 1$ in this stage is $2-3$ times more than the propagation length of $F 2$ fracture set.

Figure 11a illustrates the linear fitting curve of peak shear load and joint coefficient. Figure $11 \mathrm{~b}$ shows the variation of failure stress and crack initiation stress versus the joint coefficient. Figure 11c represents the variation of failure stress versus the joint coefficient for both the numerical and physical models. Figure 11d shows the variation of crack initiation stress versus the joint coefficient for both the numerical and physical models. The fill points and the hollow points represent the stresses in the PFC2D models and laboratory samples, respectively.

Through comparison between Figs. 7-10, and 11a, we can conclude that the capacity of bridged rock to resist shear loading has a close relationship with the failure patterns. The more the shear band number is, the more the peak of shear load is. For a large joint separation $(J C=0.85)$, the intact-bridged rock ruptures with 8 number of short shear bands; for joint separation of $J C=0.7$, the middle bridged rock ruptures with 15 number of short shear bands so an uneven shear failure surface is created. For joint separation of $J C=0.55$, two joints are connected with 21 number of shear bands. Finally, for the joint separation of $J C=0.4$, a more complex shear zone consisting of 26 shear bands, forms the final fracture surface.

The linear fitting curve between the peak of the shear load and joint coefficient in Fig. 11a shows that the peak of shear load is almost linear to the joint coefficient. The smaller the ratio is $(J C=0.4)$, the higher the peak shear load is. Note that the increase in the loading capacity of the rock bridge is not only due to the increase in the length of rock bridge. This may also be explained by the fracture mechanics theory, which indicates that the small joint lengths are corresponding to the small values of the stress intensity factors $\left(K_{\mathrm{I}}\right.$ and $\left.K_{\mathrm{II}}\right)$. This leads to higher rock bridge strength. From the fitting equation, 

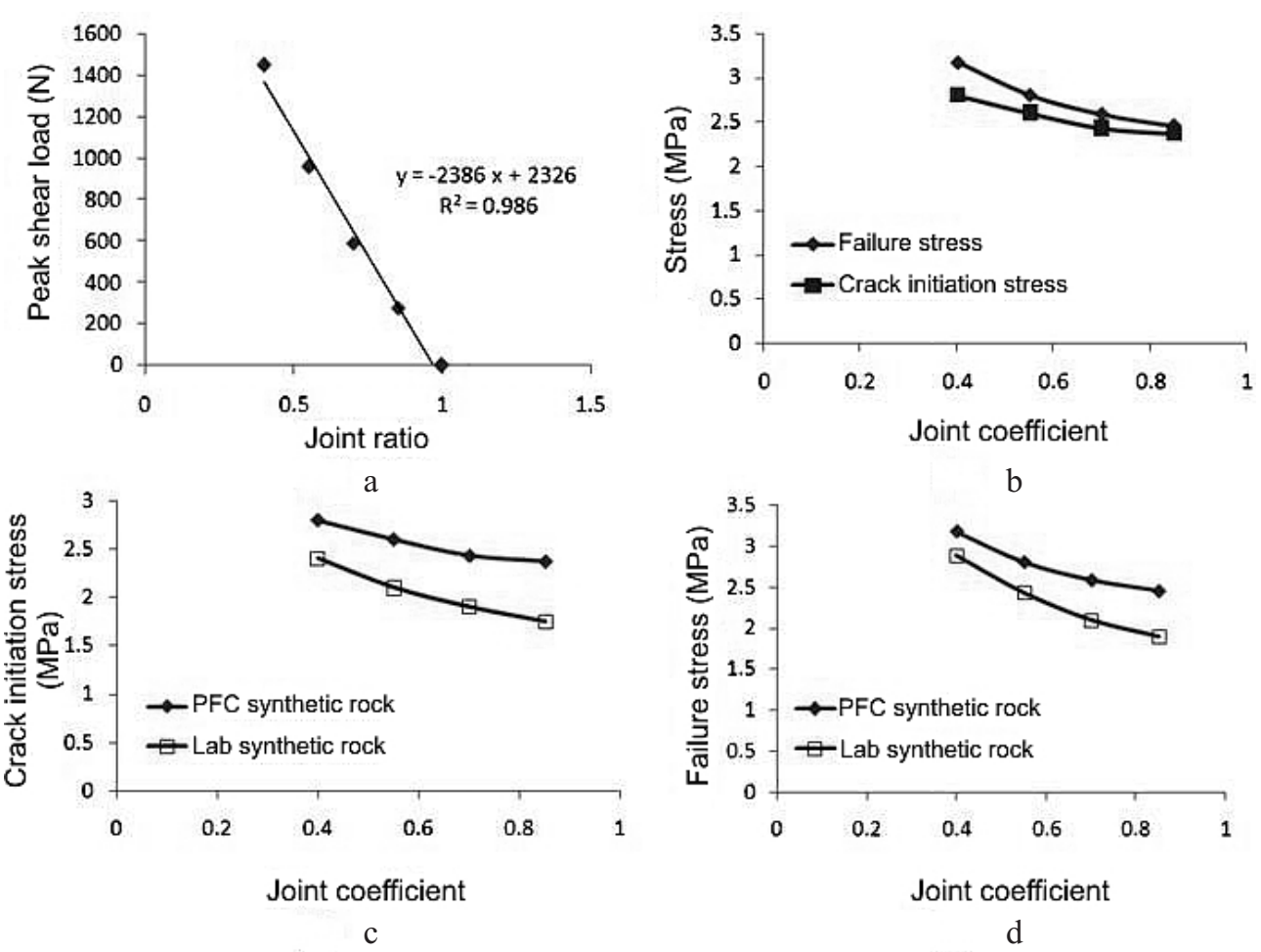

Fig. 11. (a) the linear fitting curve of peak shear load and joint coefficient; (b) the variation of failure stress and crack initiation stress versus the joint coefficient; (c) the variation of failure stress versus the joint coefficient; (d) the variation of crack initiation stress versus the joint coefficient for both the numerical and physical models.

$y=-2386 x+2326$ (Fig. 11a), it can be inferred that when the specimen has no pre-existing joints, the joint coefficient equals 0 , and the peak of shear load is $2326 \mathrm{~N}$. The shear load would be $60 \mathrm{~N}$ (approximately close to 0 ) when the ideal condition is achieved [i.e., when the joint runs through the whole specimen $(J C=1)]$. Therefore, the numerical results comply reasonably with the engineering expectation.

Figure $11 \mathrm{~b}$ shows that the failure stress and the crack initiation stress are reduced by increasing the $J C$. When the $J C$ is high, 0.85 , the difference between the crack initiation stress and failure stress is low. It shows that the final failure is occurred as soon as the cracks are initiated within the rock bridge. It means that the brittle failure has been occurred. But when the $J C$ is low, 0.4, the difference between the crack initiation stress and failure stress is high. It shows that the final failure is occurred at the more loading steps after the cracks are initiated within the rock bridge. It means the progressive failure has been occurred.

Figure 11c and d shows that the shear strength of non-persistent joints and crack initiation stress predicted by numerical simulations are nearly similar to the results obtained by experimental tests. The slight discrepancy may be due to some small variations in the mechanical specifications of numerical and laboratory specimens (i.e., the tensile strength and friction angle given in Table 2).

Finally, it may be concluded that the peak of shear load of jointed rock is mostly influenced by its failure pattern, while the failure pattern of bridged rock is mainly controlled by the joint separation. Whereas shear strength, as one of the material mechanical properties, has a close relationship with its defect configuration, the capacity of jointed 
rock masses to resist shear loading is severely influenced by its macroscopic joint constellation.

Conclusions. The shear behavior (failure progress, failure pattern, failure mechanism and shear resistance) of rock specimens containing two edge joints with different joint separations was investigated with the direct shear test by PFC2D numerical Simulation and verified by experimental tests. Based on the results obtained, the following conclusions drawn from this research are:

1. Both of the tensile and shear cracks propagate within the rock bridges but tension is the dominant mode of fracturing, irrespective of the stage of shearing.

2. When the joint coefficient is increased, the stress interaction between the joints is so strong that two fracture sets of $F 1$ and $F 2$ with low orientation are responsible for breakage of the rock bridge. By decreasing the joint coefficient, the stress interaction between the joints is decreased and consequently the mean orientation of two tensile fracture sets of $F 1$ and $F 2$ are increased.

3. By decreasing the joint coefficient, the number and the length of the two fractures sets of $F 1$ and $F 2$ are increased.

4. By decreasing the $J C$, the stable crack growth length is increased.

5. When $J C$ is high, the brittle failure has been occurred in rock bridge. But when $J C$ is low, the progressive failure has been occurred.

6. By increasing the $J C$, both of the failure stress and crack initiation stress are decreased while dilation angle is increased.

7. The shear strength of non-persistent joints and crack initiation stress predicted by numerical simulations are nearly similar to the results obtained by experimental tests.

\section{Резюме}

Досліджено вплив роз'єднання з'єднання при зсуві плоского нестабільного з'єднання під дією інтенсивного нормального навантаження з використанням програмного забезпечення PFC2D. Спочатку калібрування PFC2D проведено на основі експериментальних даних для узгодження з модельованим числовим результатом. Достовірність модельованих моделей перевірено при порівнянні з результатами прямих випробувань на зсув, що виконані на нестабільних зчленованих фізичних моделях. Завдяки числовому прямому випробуванню на зсув процес руйнування було відмічено візуально, і зруйновані зразки відбиралися подібними експериментально спостережуваним тенденціям. Дискретне моделювання елемента показує, що на руйнування зразка головним чином впливає роз'єднання з'єднання, тоді як міцність при зсуві пов'язана з моделлю руйнування і механізмом руйнування.

1. R. H. C. Wong and K. T. Chau, "Crack coalescence in rock-like material containing two cracks," Int. J. Rock Mech. Min. Sci., 35, 147-164 (1998).

2. B. Stimpson, "Failure of slopes containing discontinuous planar joints," in: Proc. of the 19th US Symp. on Rock Mechanics, Stateline, NV (1978), pp. 296-302.

3. E. Z. Lajtai, "Strength of discontinuous rocks in direct shear," Geotechnique, 19, 218-233 (1969).

4. E. Z. Lajtai, "Shear strength of weakness planes in rock," Int. J. Rock Mech. Min. Sci., 6, 499-515 (1969).

5. T. Savilahti, E. Nordlund, and O. Stephansson, "Shear box testing and modeling of joint bridge," in: N. Barton and O. Stephansson (Eds.), Rock Joints (Proc. of a Regional Conference of the International Society for Rock Mechanics, June 4-6, 1990, Loen, Norway), Balkema, Rotterdam (1990), pp. 295-300. 
6. R. H. C. Wong, W. L. Leung, and S. W. Wang, "Shear strength study on rock-like models containing arrayed open joints," in: D. Elsworth, J. P. Tinucci, and K. A. Heasley (Eds.), Rock Mechanics in the National Interest (Proc. of the 38th U.S. Rock Mechanics Symposium, July 7-10, 2001, Washington, D.C.), Swets \& Zeitlinger, Lisse, the Netherlands (2001), pp. 843-849.

7. A. Ghazvinian, M. R. Nikudel, and V. Sarfarazi, "Effect of rock bridge continuity and area on shear behavior of joints," in: Proc. of the 11th ISRM Congress (July 9-13, 2007, Lisbon, Portugal), Document ID: ISRM-11CONGRESS-2007-054 (2007).

8. A. Carpinteri and S. Valente, "Size-scale transition from ductile to brittle failure: a dimensional analysis approach," in: J. Mazars and Z. P. Bažant (Eds.), Cracking and Damage - Strain Localization and Size Effect (CNRS-NSF Workshop, Sept. 1988, Cachan, France), Elsevier, London (1989), pp. 447-490.

9. O. Mughieda and M. T. Omar, "Stress analysis for rock mass failure with offset joints," Geotech. Geol. Eng., 26, 543-552 (2008).

10. G. E. Blandford, A. R. Ingraffea, and J. A. Ligget, "Two dimensional stress intensity factor computations using the boundary element method," Int. J. Num. Meth. Eng., 17, 387-401 (1981).

11. M. H. Aliabadi and C. A. Brebbia, Advances in Boundary Element Methods for Fracture Mechanics, Elsevier, Amsterdam (1993).

12. N. Altiero and G. Gioda, "An integral equation approach to fracture propagation in rocks,” Riv. Ital. Geotecnica, 16, 55-69 (1982).

13. M. J. Yang, M. X. Chen, and Y. N. He, "Stochastic FEM analysis of grouting in fracrtured rock mass," in: H. Xie, Y. Wang, and Y. Jiang (Eds.), Computer Applications in Minerals Industries (Proc. of the 29th Int. Symp., April 25-27, 2001, Beijing, China), Swets \& Zeitlinger, Lisse, the Netherlands (2001), pp. 635-638.

14. S. Zhang, "FEM analysis on mixed-mode fracture of CSM-GRP," Eng. Fract. Mech., 23, No. 3, 523-535 (1986).

15. H. Kazuo, O. Akihiko, and A. Hiroyuki, "BEM analysis of a cylin-drical three-point bend specimen with a chevron crack for fracture toughness test of rock," Trans. JSME, 54, 1541-1545 (1988).

16. B. Shen and O. Stephansson, "Modification of the G-criterion for fracture propagation subjected to compression," Eng. Fract. Mech., 47, No. 2, 177-189 (1994).

17. B. Vasarhelyi and A. Bobet, "Modeling of crack initiation, propagation and coalescence in uniaxial compression," Rock Mech. Rock Eng., 33, No. 2, 119-139 (2000).

18. F. Erdogan and G. C. Sih, "On the crack extension path in plates under plane loading and transverse shear," J. Basic Eng.-T. ASME, 85, 519-527 (1963).

19. M. A. Hussain, S. L. Pu, and J. H. Underwood, "Strain energy release rate for a crack under combined mode I and mode II," in: Fracture Analysis, ASTM STP 560, Philadelphia, PA (1974), pp. 2-28.

20. G. C. Sih, "Strain-energy-density factor applied to mixed mode crack problems," Int. J. Fracture, 10, 305-321 (1974).

21. H. Lee and S. Jeon, "An experimental and numerical study of fracture coalescence in pre-cracked specimens under uniaxial compression," Int. J. Solids Struct., 48, No. 6, 979-999 (2011).

22. A. Ghazvinian, V. Sarfarazi, W. Schubert, and M. Blumel, "A study of the failure mechanism of planar non-persistent open joints using PFC2D," Rock Mech. Rock Eng., 45, No. 5, 677-693 (2012). 
23. A. Manouchehrian, M. Sharifzadeh, M. F. Marji, and J. Gholamnejad, "A bonded particle model for analysis of the flaw orientation effect on crack propagation mechanism in brittle materials under compression," Arch. Civ. Mech. Eng., 14, 40-52 (2014).

24. X. Zhang and L. N. Y. Wong, "Cracking process in rock-like material containing a single flaw under uniaxial compression: a numerical study based on parallel bondedparticle model approach," Rock Mech. Rock Eng., 45, No. 5, 711-737 (2012).

25. X. Zhang and L. N. Y. Wong, "Crack initiation, propagation and coalescence in rock-like material containing two flaws: a numerical study based on bonded-particle, model approach," Rock Mech. Rock Eng., 46, No. 5, 1001-1021 (2013).

26. S. Q. Yang, Y. H. Huang, H. W. Jing, and X. R. Liu, "Discrete element modeling on fracture coalescence behaviour of red sandstone containing two unparallel fissures under uniaxial compression," Eng. Geol., 178, 28-48 (2014).

27. V. Sarfarazi, A. Ghazvinian, W. Schubert, et al., "Numerical simulation of the process of fracture of echelon rock joints," Rock Mech. Rock Eng., 47, No. 4, 1355-1371 (2014).

28. Particle Flow Code in 2-Dimensions (PFC2D), Version 3.10, Itasca Consulting Group Inc., Minneapolis, MN (2004).

29. P. Cundall, "A computer model for simulating progressive large scale movements in blocky rock systems," in: Proc. of the Symp. of International Society of Rock Mechanics, Vol. 1, Paper No. II-8, Nancy, France (1971).

30. D. O. Potyondy and P. A. Cundall, "A bonded-particle model for rock," Int. J. Rock Mech. Min. Sci., 41, No. 8, 1329-1364 (2004). 